\title{
O ESTADO DA ARTE EM POLÍTICAS SOCIAIS DE ESPORTE E LAZER NO BRASIL (2000-2009)
}

\author{
Suélen Barboza Eiras de Castro \\ Universidade Federal do Paraná, Curitiba, Paraná, Brasil \\ Neuza Rosa Nery de Lima Moro \\ Universidade Federal do Paraná, Curitiba, Paraná, Brasil \\ Liliane Roberta Tsumanuma da Silveira \\ Universidade Federal do Paraná, Curitiba, Paraná, Brasil \\ Fernando Marinho Mezzadri \\ Universidade Federal do Paraná, Curitiba, Paraná, Brasil
}

\begin{abstract}
Resumo
Este trabalho tem como objetivo realizar um mapeamento das teses, dissertações e artigos disponibilizados on-line que abordam políticas sociais de esporte e lazer no Brasil, no período de 2000 a 2009. Ao todo foram selecionados 32 trabalhos. Podese concluir que, apesar de existir um aumento no número de estudos que abordam a temática de políticas sociais de esporte e lazer, percebe-se que essa temática não tem sido uma constante nas produções científicas. Há uma predominância de trabalhos de natureza qualitativa e a inexistência de trabalhos de natureza quantitativa. O lazer tem sido o principal objeto de estudo nos trabalhos sobre as políticas sociais. Outra conclusão foi que a maior parte dos trabalhos, ao problematizar as políticas sociais de esporte e lazer, investiga tais ações a partir da análise de sua gestão e/ou organização e/ou estrutura.
\end{abstract}

Palavras-chave: Política Social. Esporte. Lazer.

\section{Introdução}

$\mathrm{O}$

esporte no Brasil, em meados do século XIX, apresentava-se "como prática social incipiente, com baixos níveis de conflito e de demandas, ausência de interesses secundários e pequena intervenção por parte do Estado" (LINHALES, 1996, p. 204). Entretanto, ao longo do tempo essa realidade foi se transformando. De uma atividade desinteressada, o esporte tornou-se alvo de interesses cada vez mais amplos, passando de uma atividade com um fim em si mesmo para um instrumento de efetivação de fins externos a ele (LINHALES, 2001).

Atualmente, percebe-se que o esporte encontra-se solidamente inserido na sociedade, sendo considerado um fenômeno sociocultural e 
entendido como um direito social. De acordo com o Art. 217 da Constituição Federal, "é dever do Estado fomentar práticas desportivas formais e não formais, como direito de cada um" (BRASIL, 1988). O direito ao lazer também se encontra na Constituição Federal por meio do seu Art. $6^{\circ}$, que assim estabelece: "São direitos sociais a educação, a saúde, o trabalho, a moradia, o lazer, a segurança, a previdência social, a proteção à maternidade e à infância, a assistência aos desamparados, na forma desta Constituição" (BRASIL, 1988). A intervenção por parte do Estado nos âmbitos do esporte e do lazer "dilui os contornos dessas esferas de ação, de forma que os interesses e necessidades aí representados não podem mais ser considerados como intocáveis ou pertencentes ao domínio privado de alguns grupos" (LINHALES, 1998, p. 77). Ao se considerarem o esporte e o lazer como direitos sociais, pressupõe-se a garantia e a provisão por parte do Estado de políticas que deem suporte a tais benefícios sociais (LINHALES, 1998).

De um modo geral, as políticas públicas podem ser entendidas como intervenções do Estado na sociedade por meio de ações implementadas diretamente pelo governo ou por um conjunto de instituições estatais, sob a justificativa de, por um lado, atender as demandas, necessidades ou interesses e, por outro, manter as condições de estabilidade adequadas a fim de garantir a produção e a reprodução social. Tal intervenção traz consigo um ponto de partida e uma posição político-ideológica norteadora (STIGGER, 1998). As políticas públicas podem ser classificadas de acordo com o seu alcance, ou seja, enquanto políticas universais ou focalizadas. Estas também podem ser classificadas de acordo com os setores envolvidos, ou seja, políticas setoriais ou intersetoriais. As políticas públicas podem ainda ser classificadas como políticas sociais quando se encontram sustentadas em determinadas convicções, valores e interesses (STIGGER, 1998). De acordo com Hölfing (2001, p. 31),

políticas sociais se referem a ações que determinam o padrão de proteção social implementado pelo Estado, voltadas, em princípio, para a redistribuição dos benefícios sociais visando a diminuição das desigualdades estruturais produzidas pelo desenvolvimento socioeconômico.

Embora presente em diferentes políticas sociais, o esporte e o lazer 
são comumente utilizados como atividades meio, ou seja, como atividades que buscam a realização de fins externos a elas próprias. De acordo com Linhales (2001), nessas ações, tais atividades são dirigidas a grupos específicos e isolados, em função do caráter seletivo de tais programas. A autora ainda aponta que essa focalização no público a ser atendido dificulta a consolidação do esporte e do lazer como um direito social.

Estando sob responsabilidade da Secretaria Nacional de Desenvolvimento de Esporte e Lazer, o Departamento de Políticas Sociais de Esporte e Lazer tem como objetivo promover políticas sociais que garantam o esporte e o lazer como direitos sociais. Ou seja, essas políticas sociais devem garantir o acesso da população brasileira em todos os segmentos etários e em uma perspectiva intergeracional, de modo a promover ações contínuas de esporte e lazer que respondam às necessidades localizadas nesse campo da vida social. O principal programa desse departamento é o Programa Esporte e Lazer da Cidade (Pelc). Criado em 2003, tem como objetivo minimizar a desigualdade em relação ao acesso ao esporte e lazer de uma parcela significativa da população brasileira (MINISTÉRIO DO ESPORTE, 2010).

As discussões acerca das políticas públicas nas áreas de Educação Física, esporte e lazer vêm se consolidando no meio acadêmico, nele ganhando espaço e relevância. As pesquisas nessa área também têm aumentado consideravelmente nas últimas décadas (AMARAL; PERREIRA, 2009). Apesar de haver esse crescimento da produção acadêmica, ele não tem sido acompanhado por um aprofundamento teórico-metodológico (GODOY; VENDRUSCOLO, 2011).

O objetivo deste trabalho é o de contribuir com esse campo do conhecimento por meio da apresentação de um "estado da arte" de políticas sociais de esporte e lazer no Brasil durante o período de 2000 a 2009. Acreditamos que, tal como aponta Ferreira (2009), pesquisas que buscam estabelecer o estado da arte podem contribuir com apontamentos úteis para os pesquisadores que lidam com objetos de estudos semelhantes e com a consolidação de uma área de conhecimento, pois novas possibilidades de reflexão podem ser direcionadas (FERREIRA, 2009).

\section{Metodologia}

Esta pesquisa, de natureza quantitativa e qualitativa, caracteriza-se 
como um estudo que visa estabelecer o estado da arte de políticas sociais de esporte e lazer no Brasil no período de 2000 a 2009. As pesquisas de estado da arte são de caráter bibliográfico e buscam mapear e discutir a produção acadêmica de diferentes áreas de conhecimento. Ou seja, constituem-se em, "pesquisas de levantamento e de avaliação do conhecimento sobre determinado tema" (FERREIRA, 2002, p. 259). Através delas é possível identificar as condições e formas em que as pesquisas científicas têm sido produzidas e quais os aspectos e dimensões de um objeto de estudo elas têm privilegiado em diferentes épocas e lugares (FERREIRA, 2002).

Com o objetivo de realizar um levantamento e avaliação da produção acadêmica sobre as políticas sociais de esporte e lazer no Brasil de 2000 a 2009, selecionamos dissertações, teses e artigos de periódicos produzidos na "Área 21". Somente foram utilizados os trabalhos que estavam disponibilizados on-line, seja o seu resumo ou o trabalho na íntegra.

Em relação às dissertações e teses, utilizamos duas fontes: o Banco de Teses do Portal da Capes $^{2}$ e a Biblioteca Digital Brasileira de Teses e Dissertações (BDBTD) ${ }^{3}$. A busca envolveu o campo "Assunto" e foram usadas as palavras-chave "políticas públicas de esporte", "políticas públicas de lazer", "políticas de esporte", "políticas de lazer". Foram encontrados 35 trabalhos. Em relação aos artigos de periódicos, delimitamos a busca àqueles periódicos nacionais voltados a publicar pesquisas científicas sobre temas relacionados à Educação Física e com classificação B1 e/ou B2. Assim, a busca ocorreu nos seguintes periódicos: Revista Motriz, Revista Movimento, Revista Brasileira de Ciências do Esporte, Revista Brasileira de Educação Física e Esporte e Revista da Educação Física/UEM. Utilizamos o campo de "Pesquisa" para, através das palavras-chave citadas acima, realizarmos as buscas. Encontramos 12 trabalhos. Apesar de a busca envolver as palavraschave apresentadas acima, durante o levantamento alguns trabalhos foram descartados, pois o objeto de estudo central deles não envolvia políticas públicas sociais de esporte e lazer. Portanto, analisamos 32 teses e dissertações ( 25 dissertações e 7 teses) e 9 artigos de periódicos.

1-Área de conhecimento que envolve as especialidades das seguintes áreas profissionais: Educação Física, Fisioterapia, Fonoaudiologia e Terapia Ocupacional.

2-http://capesdw.capes.gov.br/capesdw

3-http://bdtd.ibict.br

Pensar a Prática, Goiânia, v. 15, n. 2, p. 272-550, abr.jun. 2012 
Após esse levantamento, organizamos os dados de pesquisa em uma planilha do Microsoft Office Excel 2007. Separamos os dados em relação à sua caracterização, ou seja, dissertações, teses e artigos de periódicos. Todos os trabalhos foram organizados da seguinte maneira: título; autor(es); ano de publicação; se completo ou resumo; natureza da pesquisa (quantitativa ou qualitativa); tipo de pesquisa (bibliográfico, documental, campo e documental e campo); objeto de estudo (política de esporte, lazer e esporte/lazer) e objetivo geral do trabalho. Nas dissertações e teses, além desses dados acrescentamos a instituição de ensino superior e área de conhecimento do trabalho. Nos artigos de periódicos acrescentamos o nome do periódico, o número e o volume de publicação.

Depois de organizarmos os dados, focamos nossa análise nos anos e locais de publicação dos trabalhos, na natureza e nos tipos de pesquisa utilizados, nos objetos de estudo e no objetivo geral do trabalho.

\section{Resultados}

A partir dos critérios de busca apresentados anteriormente, encontramos 41 trabalhos que discutiam políticas sociais de esporte e lazer, sendo 7 teses, 25 dissertações e 9 artigos de periódicos. Destes, 16 não se encontravam disponibilizados integralmente nas bases on-line. Obtivemos apenas o acesso ao seu resumo. Os trabalhos selecionados encontram-se no Quadro 1.

\begin{tabular}{|c|c|l|c|}
\hline & TÍTULO & \multicolumn{1}{|c|}{ AUTOR } & TIPO \\
\hline 1 & $\begin{array}{c}\text { AMARAL, S. C. } \\
\text { F. }\end{array}$ & $\begin{array}{l}\text { Avanços e contradições da participação popular na } \\
\text { definição de políticas públicas de lazer em Porto } \\
\text { Alegre }\end{array}$ & Artigo \\
\hline 2 & $\begin{array}{c}\text { AMARAL, S. C. } \\
\text { F.; PEREIRA, } \\
\text { A. P. C. }\end{array}$ & $\begin{array}{l}\text { Reflexões sobre a produção em políticas públicas } \\
\text { de educação física, esporte e lazer }\end{array}$ & Artigo \\
\hline 3 & $\begin{array}{c}\text { AMARAL, S. C. } \\
\text { F. }\end{array}$ & $\begin{array}{l}\text { Políticas públicas de lazer e participação cidadã: } \\
\text { entendendo o caso de Porto Alegre }\end{array}$ & Tese \\
\hline 4 & $\begin{array}{c}\text { BARBOSA, E. } \\
\text { J. }\end{array}$ & $\begin{array}{l}\text { Esporte e recreação no município de Ponta } \\
\text { Grossa-PR: análise de duas gestões 1993-1993 / } \\
1997-2000\end{array}$ & $\begin{array}{c}\text { Dissertação } \\
\text { (resumo) }\end{array}$ \\
\hline 5 & $\begin{array}{c}\text { BARBOSA, F. } \\
\text { S. }\end{array}$ & $\begin{array}{l}\text { Políticas públicas de lazer em cidade média de } \\
\text { região metropolitana }\end{array}$ & Dissertação \\
\hline 6 & $\begin{array}{c}\text { BASTOS, F. da } \\
\text { C. }\end{array}$ & $\begin{array}{l}\text { Gestão democrática e política municipal de } \\
\text { esporte: o caso de Santana de Parnaíba }\end{array}$ & Tese \\
\hline 7 & $\begin{array}{c}\text { BATISTA, M. } \\
\text { da C. A. }\end{array}$ & $\begin{array}{l}\text { A relação governo e sociedade na gestão da } \\
\text { política de esporte e lazer no governo do estado - } \\
\text { gestão 1999-2001: analisando o projeto "Idosos } \\
\text { em Movimento" }\end{array}$ & $\begin{array}{l}\text { Dissertação } \\
\text { (resumo) }\end{array}$ \\
\hline
\end{tabular}

Pensar a Prática, Goiânia, v. 15, n. 2, p. 272-550, abr./jun. 2012 


\begin{tabular}{|c|c|c|c|}
\hline 8 & $\begin{array}{l}\text { BATISTA, M. } \\
\text { da C. A. }\end{array}$ & $\begin{array}{l}\text { A relação governo e sociedade na gestão da } \\
\text { política pública de esportes e lazer no governo do } \\
\text { estado de Pernambuco - 1999-2001: analisando o } \\
\text { projeto "Idosos em Movimento" }\end{array}$ & Artigo \\
\hline 9 & BROD, A. & $\begin{array}{l}\text { Políticas de lazer para idosos na região do Vale do } \\
\text { Taquari: um estudo descritivo dos grupos de } \\
\text { convivência e bailes da terceira idade }\end{array}$ & $\begin{array}{l}\text { Dissertação } \\
\text { (resumo) }\end{array}$ \\
\hline 10 & BUENO, L. & $\begin{array}{l}\text { Políticas públicas do esporte no Brasil - se a } \\
\text { "pelada" é pública, a bola continua privada? }\end{array}$ & Tese \\
\hline 11 & COSTA, E. T. & $\begin{array}{l}\text { Na rede, pelo lado de fora? Gestão matricial e } \\
\text { políticas públicas de lazer na cidade de Santo } \\
\text { André }\end{array}$ & Dissertação \\
\hline 12 & FRANÇA. J. P. & $\begin{array}{l}\text { Políticas públicas de lazer no município de } \\
\text { Belém? Concepções e intervenções }\end{array}$ & Dissertação \\
\hline 13 & $\begin{array}{l}\text { LEIROS, A. C. } \\
\text { R. }\end{array}$ & $\begin{array}{l}\text { Lazer e educação nos parques públicos de } \\
\text { Salvador }\end{array}$ & $\begin{array}{c}\text { Dissertação } \\
\text { (resumo) }\end{array}$ \\
\hline 14 & $\begin{array}{l}\text { LIÁO JUNIOR, } \\
\text { R. }\end{array}$ & $\begin{array}{l}\text { Políticas públicas de educação física, esporte e } \\
\text { lazer: tensões e desafios de um projeto contra- } \\
\text { hegemônico no Distrito Federal, } 1995 \text { - } 1998\end{array}$ & Artigo \\
\hline 15 & $\begin{array}{l}\text { LUCAS, F. da } \\
\text { M. }\end{array}$ & $\begin{array}{l}\text { A prática do lazer em áreas urbanas sujeitas à } \\
\text { exclusão social em Presidente Prudente - SP }\end{array}$ & $\begin{array}{l}\text { Dissertação } \\
\text { (resumo) }\end{array}$ \\
\hline 16 & $\begin{array}{l}\text { MARIANO, S. } \\
\text { H. }\end{array}$ & $\begin{array}{l}\text { Políticas públicas de lazer em cidades de pequeno } \\
\text { porte de regiões metropolitanas }\end{array}$ & Dissertação \\
\hline 17 & $\begin{array}{l}\text { MARIANO, S. } \\
\text { H.; } \\
\text { MARCELLINO, } \\
\text { N. C. }\end{array}$ & $\begin{array}{l}\text { Equipamentos de lazer em cidades pequenas de } \\
\text { região metropolitana }\end{array}$ & Artigo \\
\hline 18 & MELO, M. P. de & $\begin{array}{l}\text { A Vila Olímpica da Maré e as políticas públicas } \\
\text { de esporte no Rio de Janeiro: um debate sobre a } \\
\text { relação lazer, esporte e escola }\end{array}$ & Artigo \\
\hline 19 & $\begin{array}{l}\text { MELO,V.A. de; } \\
\text { PERES, F. de F. }\end{array}$ & $\begin{array}{l}\text { A cidade e o lazer: as desigualdades } \\
\text { socioespaciais na distribuição dos equipamentos } \\
\text { culturais na cidade do Rio de Janeiro e a } \\
\text { construção de um indicador que oriente as ações } \\
\text { em politicas públicas }\end{array}$ & Artigo \\
\hline 20 & $\begin{array}{l}\text { MENEZES, V. } \\
\text { G. de }\end{array}$ & Políticas públicas para esporte/lazer & $\begin{array}{l}\text { Dissertação } \\
\text { (resumo) }\end{array}$ \\
\hline 21 & $\begin{array}{l}\text { MEZZADRI, F. } \\
\text { M. }\end{array}$ & $\begin{array}{l}\text { Histórias das políticas públicas do esporte e lazer } \\
\text { no estado do Paraná }\end{array}$ & $\begin{array}{c}\text { Tese } \\
\text { (Resumo) }\end{array}$ \\
\hline 22 & $\begin{array}{l}\text { MINUTTI, M. } \\
\text { R. }\end{array}$ & $\begin{array}{l}\text { Políticas públicas de lazer para crianças: o caso de } \\
\text { Adamantina }\end{array}$ & $\begin{array}{c}\text { Dissertação } \\
\text { (resumo) }\end{array}$ \\
\hline 23 & $\begin{array}{l}\text { MOLINA, R. M. } \\
\text { K. }\end{array}$ & $\begin{array}{l}\text { A participação cidadã nos marcos das políticas de } \\
\text { lazer: implicações e protagonismos - o caso do } \\
\text { Projeto Centro de Comunidade, na cidade de } \\
\text { Porto Alegre }\end{array}$ & Artigo \\
\hline 24 & $\begin{array}{l}\text { MOREIRA, F. } \\
\text { de S. }\end{array}$ & $\begin{array}{l}\text { Políticas públicas de lazer em Belém: um estudo } \\
\text { sobre a gestão coletiva implementada pelo poder } \\
\text { público municipal no período de } 2001 \text { a } 2004\end{array}$ & Dissertação \\
\hline 25 & MUELLER, A. & $\begin{array}{l}\text { Diagnóstico de esporte e lazer: conhecer para } \\
\text { transformar um estudo em municípios do Rio } \\
\text { Grande do Sul }\end{array}$ & $\begin{array}{c}\text { Tese } \\
\text { (resumo) }\end{array}$ \\
\hline 26 & $\begin{array}{l}\text { MUNHOZ, V. } \\
\text { C. C. }\end{array}$ & $\begin{array}{l}\text { O lazer como direito social na prefeitura } \\
\text { municipal de Belo Horizonte }\end{array}$ & $\begin{array}{l}\text { Dissertação } \\
\text { (resumo) }\end{array}$ \\
\hline
\end{tabular}




\begin{tabular}{|c|c|c|c|}
\hline 27 & $\begin{array}{l}\text { OLIVEIRA, F. } \\
\text { P. de }\end{array}$ & $\begin{array}{l}\text { Utopia, esperança e resistência: um estudo sobre a } \\
\text { práxis libertadora na política pública de esporte e } \\
\text { lazer de Fortaleza }\end{array}$ & Dissertação \\
\hline 28 & $\begin{array}{l}\text { OLIVEIRA, L. } \\
\text { M. de }\end{array}$ & $\begin{array}{l}\text { A gestão das políticas públicas do lazer no Rio } \\
\text { Grande do Sul }\end{array}$ & $\begin{array}{l}\text { Dissertação } \\
\text { (resumo) }\end{array}$ \\
\hline 29 & ROCHA, L. C. & $\begin{array}{l}\text { Educação e políticas públicas do lazer no subúrbio } \\
\text { ferroviário: (in)visibilidade na dinâmica da cidade } \\
\text { do Salvador }\end{array}$ & $\begin{array}{l}\text { Dissertação } \\
\text { (resumo) }\end{array}$ \\
\hline 30 & $\begin{array}{l}\text { RODRIGUES, } \\
\text { E. H. C. }\end{array}$ & $\begin{array}{l}\text { Construindo uma política pública de lazer, espaço } \\
\text { ou programa - o que garante a animação? Uma } \\
\text { retrospectiva histórica do município de } \\
\text { Sorocaba/SP }\end{array}$ & Dissertação \\
\hline 31 & $\begin{array}{l}\text { RODRIGUES, } \\
\text { E. H. C.; } \\
\text { BRAMANTE, } \\
\text { A. C. }\end{array}$ & $\begin{array}{l}\text { O espaço na construção de uma política de lazer: } \\
\text { estudando Sorocaba/SP }\end{array}$ & Artigo \\
\hline 32 & $\begin{array}{l}\text { SANTOS, H. T. } \\
\text { dos }\end{array}$ & $\begin{array}{l}\text { A democratização do esporte e lazer em Porto } \\
\text { Alegre: um estudo das políticas no período de } \\
1989 \text { a } 2000\end{array}$ & Dissertação \\
\hline 33 & $\begin{array}{l}\text { SILVA, J. A. de } \\
\text { A. da }\end{array}$ & $\begin{array}{l}\text { Políticas públicas de esporte e lazer: resistência e } \\
\text { dominação no governo de Arraes em Pernambuco } \\
\text { entre } 1995 \text { e } 1998\end{array}$ & $\begin{array}{l}\text { Dissertação } \\
\text { (resumo) }\end{array}$ \\
\hline 34 & $\begin{array}{l}\text { SILVA, J.A. de } \\
\text { A. da }\end{array}$ & $\begin{array}{l}\text { Politica de esporte e lazer como educação } \\
\text { emancipatória da juventude: contradições e } \\
\text { possibilidades das politicas democráticas e } \\
\text { populares }\end{array}$ & Tese \\
\hline 35 & $\begin{array}{l}\text { SILVA, L. A. R. } \\
\text { da. }\end{array}$ & $\begin{array}{l}\text { Educação Para o Lazer do Cidadão: políticas } \\
\text { públicas para a cidade de São Luís (MA) }\end{array}$ & Dissertação \\
\hline 36 & $\begin{array}{l}\text { TEREZANI, D. } \\
\text { R. }\end{array}$ & $\begin{array}{l}\text { Popularizacão da canoagem como esporte e lazer: } \\
\text { o caso de Piracicaba }\end{array}$ & Dissertação \\
\hline 37 & TERRA, R. B. & $\begin{array}{l}\text { O impacto da política pública de lazer no processo } \\
\text { educativo dos usuários do centro popular de } \\
\text { cultura, esporte e lazer do bairro Aero-rancho. }\end{array}$ & Dissertação \\
\hline 38 & $\begin{array}{l}\text { VERONEZ, L. } \\
\text { F. C. }\end{array}$ & $\begin{array}{l}\text { Quando o estado joga a favor do privado: as } \\
\text { políticas de esporte após a Constituição de } 1988\end{array}$ & Tese \\
\hline 39 & VICENTINI, M. & $\begin{array}{l}\text { Conselho Municipal de Esportes de Vitória: } \\
\text { limites e possibilidades da participação popular na } \\
\text { gestão pública }\end{array}$ & $\begin{array}{l}\text { Dissertação } \\
\text { (resumo) }\end{array}$ \\
\hline 40 & VIEIRA, E. M. & $\begin{array}{l}\text { Categorias fundamentais para a construção de } \\
\text { políticas públicas de lazer na região do Cariri } \\
\text { cearense: uma perspectiva progressista }\end{array}$ & $\begin{array}{l}\text { Dissertação } \\
\text { (resumo) }\end{array}$ \\
\hline 41 & XAVIER, D. R. & $\begin{array}{l}\text { Políticas de lazer e segregação socioespacial: o } \\
\text { caso de Campos dos Goytacazes, RJ }\end{array}$ & $\begin{array}{l}\text { Dissertação } \\
\text { (resumo) }\end{array}$ \\
\hline
\end{tabular}

Quadro 1: Trabalhos selecionados

Em relação ao ano de publicação das teses, dissertações e artigos de periódicos selecionados, notamos que a quantidade de trabalhos oscila entre os anos. Os anos de 2003, 2004, 2005, 2006 e 2008 foram os que apresentaram a maior quantidade de trabalhos acerca da temá- 
tica de políticas sociais de esporte e lazer. Podemos observar também que as dissertações são as publicações mais frequentes (Quadro 2).

\begin{tabular}{|l|c|c|c|c|c|c|c|c|c|c|c|}
\hline & $\mathbf{2 0 0 0}$ & $\mathbf{2 0 0 1}$ & $\mathbf{2 0 0 2}$ & $\mathbf{2 0 0 3}$ & $\mathbf{2 0 0 4}$ & $\mathbf{2 0 0 5}$ & $\mathbf{2 0 0 6}$ & $\mathbf{2 0 0 7}$ & $\mathbf{2 0 0 8}$ & $\mathbf{2 0 0 9}$ & Total \\
\hline Dissert. & 01 & 03 & 01 & 04 & 04 & - & 04 & 01 & 05 & 02 & $\mathbf{2 5}$ \\
\hline Teses & 01 & - & - & 01 & - & 03 & 01 & - & 01 & - & $\mathbf{0 7}$ \\
\hline Artigos & - & - & - & 02 & 01 & 04 & - & - & 01 & 01 & $\mathbf{0 9}$ \\
\hline Total & $\mathbf{0 2}$ & $\mathbf{0 3}$ & $\mathbf{0 1}$ & $\mathbf{0 7}$ & $\mathbf{0 5}$ & $\mathbf{0 7}$ & $\mathbf{0 5}$ & $\mathbf{0 1}$ & $\mathbf{0 7}$ & $\mathbf{0 3}$ & $\mathbf{4 1}$ \\
\hline
\end{tabular}

Quadro 2: Número e tipos de publicações por ano

Em relação aos locais de publicação das teses selecionadas, verificamos que, dentre todas as instituições de ensino superior, apenas 5 apresentam trabalhos de doutorado acerca das políticas sociais de esporte e lazer. A Universidade Estadual de Campinas (Unicamp) é a instituição que apresenta o maior número de publicações de teses -3 no total. As demais instituições - Fundação Getúlio Vargas (FGV), Universidade Federal da Bahia (UFBA), Universidade Gama Filho (UGF) e Universidade de São Paulo (USP) - possuem apenas um trabalho de doutorado (Figura 1).

Quanto aos locais de publicação das dissertações selecionadas, constatamos que a Universidade Metodista de Piracicaba (Unimep) é a instituição com o maior número de publicações de dissertações -4 no total. Outras instituições se destacam: Universidade Federal de Pernambuco (UFPE), com 3 trabalhos; Universidade Federal da Bahia (UFBA), Universidade Federal do Rio Grande do Sul (UFRGS) e Universidade Estadual de Campinas (Unicamp), com 2 trabalhos. As demais instituições possuem apenas 1 dissertação (Figura 1).

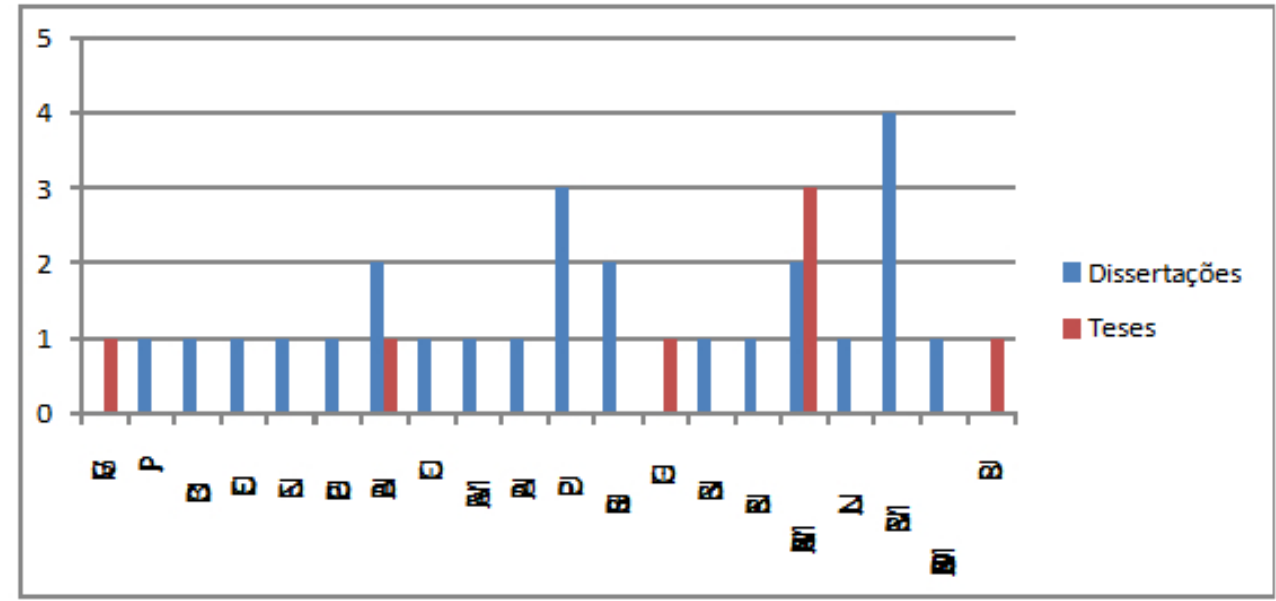

Figura 1: Local de publicação de teses e dissertações

Pensar a Prática, Goiânia, v. 15, n. 2, p. 272-550, abr./jun. 2012 
Em relação à área de conhecimento em que os trabalhos foram desenvolvidos, notamos que a maior parte deles encontra-se nas áreas da Educação (11) e da Educação Física (9). Em relação às teses, percebemos que a maior parte foi desenvolvida nas áreas da Educação (3) e da Educação Física (3). Em relação às dissertações, encontramos que a maior parte foi desenvolvida nas áreas da Educação (8) e das Ciências Sociais e Política (7) (Quadro 3).

\begin{tabular}{|l|c|c|c|c|c|c|c|c|}
\hline & Educação & $\begin{array}{c}\text { Educação } \\
\text { Física }\end{array}$ & $\begin{array}{c}\text { Ciências } \\
\text { Sociais e } \\
\text { Política }\end{array}$ & $\begin{array}{c}\text { Adminis- } \\
\text { tração } \\
\text { Pública }\end{array}$ & Geografia & Psicologia & $\begin{array}{c}\text { Serviço } \\
\text { Social }\end{array}$ & $\begin{array}{c}\text { Tota } \\
\mathbf{1}\end{array}$ \\
\hline Dissert. & 8 & 6 & 7 & 1 & 1 & 1 & 1 & $\mathbf{2 5}$ \\
\hline Teses & 3 & 3 & - & 1 & - & - & - & $\mathbf{7}$ \\
\hline Total & $\mathbf{1 1}$ & $\mathbf{9}$ & $\mathbf{7}$ & $\mathbf{2}$ & $\mathbf{1}$ & $\mathbf{1}$ & $\mathbf{1}$ & $\mathbf{3 2}$ \\
\hline
\end{tabular}

Quadro 3: Áreas de conhecimento das dissertações e teses

Em relação aos periódicos onde foram publicados os artigos, constatamos que a Revista Movimento é o que contém o maior número de trabalhos sobre políticas sociais de esporte e lazer -5 no total. Encontramos 3 trabalhos na Revista Brasileira de Ciências do Esporte e 1 na Revista Motriz. Na Revista Brasileira de Educação Física e Esporte e na Revista de Educação Física /UEM não encontramos trabalho algum relacionado à temática de políticas sociais de esporte e lazer (Figura 2).

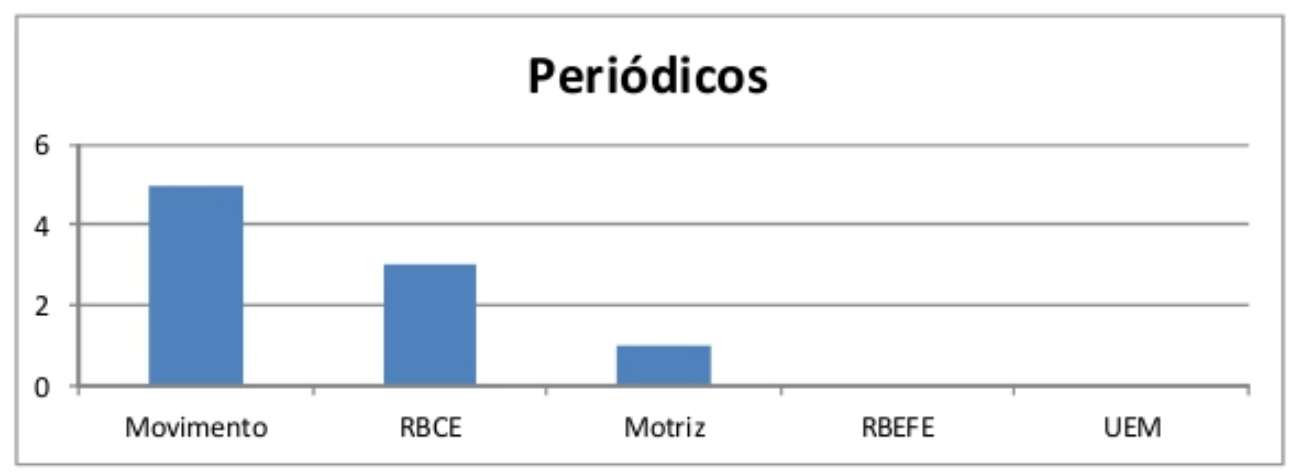

Figura 2: Periódicos com artigos sobre a temática de políticas sociais de esporte e lazer

No tocante à metodologia dos trabalhos, notamos uma predominância de trabalhos de natureza qualitativa. Ou seja, do total de 41 trabalhos selecionados constatamos que 36 são qualitativos. Não encontramos trabalho algum de natureza quantitativa. Em relação às teses, 6 delas são de natureza qualitativa e 1 de natureza 
quantiqualitativa. Em relação às dissertações, 22 delas são de natureza qualitativa e 3 de natureza quantiqualitativa. Já em relação aos 9 artigos de periódicos, 8 são de natureza qualitativa e 1 é de natureza quantiqualitativa (Quadro 4).

\begin{tabular}{|l|c|c|c|c|}
\hline & Qualitativa & Quantitativa & Quantiqualitativa & Total \\
\hline Dissertações & 22 & - & 3 & $\mathbf{2 5}$ \\
\hline Teses & 6 & - & 1 & $\mathbf{7}$ \\
\hline Artigos de periódicos & 8 & - & 1 & $\mathbf{9}$ \\
\hline Total & $\mathbf{3 6}$ & $\mathbf{0}$ & $\mathbf{5}$ & $\mathbf{4 1}$ \\
\hline
\end{tabular}

Quadro 4: Natureza da pesquisa

Ainda em relação à metodologia, analisamos os trabalhos de acordo com o tipo de pesquisa realizada. Encontramos basicamente quatro tipos de pesquisa: bibliográfica, documental, campo, e documental e campo. Os trabalhos classificados como "bibliográficos" são aqueles que buscam, através de materiais já publicados (livros, artigos, teses e dissertações), abordar um objeto de estudo. Os trabalhos classificados como do tipo "documental" são aqueles que investigam um objeto de estudo através de documentos escritos e não escritos. Os trabalhos classificados como de "campo" são aqueles que buscam, através de alguns instrumentos como questionários, observações e entrevistas, investigar um objeto de estudo. Alguns trabalhos ainda foram classificados como "documental e campo", pois utilizaram os dois tipos de pesquisa.

A partir da análise dos trabalhos, encontramos que a maioria combina uma análise documental com uma análise em campo. Ou seja, dos 41 trabalhos, 22 são de caráter documental e campo. Ainda constatamos que os artigos de periódicos foram os trabalhos que apresentaram uma maior variedade nas modalidades de pesquisa (Quadro 5).

\begin{tabular}{|l|c|c|c|c|c|}
\hline & Bibliográfica & Documental & Campo & $\begin{array}{c}\text { Documental e } \\
\text { campo }\end{array}$ & Total \\
\hline Dissertações & - & 5 & 4 & 16 & $\mathbf{2 5}$ \\
\hline Teses & - & 3 & 1 & 3 & 7 \\
\hline $\begin{array}{l}\text { Artigos de } \\
\text { periódicos }\end{array}$ & 1 & 3 & 2 & 3 & $\mathbf{9}$ \\
\hline Total & $\mathbf{1}$ & $\mathbf{1 1}$ & $\mathbf{7}$ & $\mathbf{2 2}$ & $\mathbf{4 1}$ \\
\hline
\end{tabular}

Quadro 5: Tipos de pesquisa

Os trabalhos foram ainda analisados de acordo com o objeto central de estudo. Ou seja, alguns trabalhos voltaram suas investigações para políticas/programas específicos de esporte, e assim os classifica- 
mos como "esporte". Outros trabalhos optaram por investigar políticas/programas específicos de lazer, e assim os classificamos como "lazer". Ainda encontramos trabalhos que focaram políticas/programas de esporte e lazer, e assim os classificamos como "esporte/lazer".

Notamos que a maior parte dos trabalhos, 24 no total, teve como objeto de estudo a análise de políticas/programas de lazer. Os trabalhos voltados às políticas/programas de lazer se destacam entre as dissertações (17) e entre os artigos de periódicos (5). Em relação às teses, no entanto, encontramos que a maior parte delas volta a sua atenção para as políticas/programas de esporte. Ou seja, das 7 teses analisadas, 4 têm o esporte como objeto de estudo. $\mathrm{O}$ esporte não foi encontrado como objeto central de estudo em nenhum dos artigos de periódicos selecionados (Quadro 6).

\begin{tabular}{|l|c|c|c|c|}
\hline & Esporte & Lazer & Esporte/lazer & Total \\
\hline Dissertações & 2 & 17 & 6 & $\mathbf{2 5}$ \\
\hline Teses & 4 & 2 & 1 & $\mathbf{7}$ \\
\hline $\begin{array}{l}\text { Artigos } \\
\text { periódicos }\end{array}$ & - & 5 & 4 & $\mathbf{9}$ \\
\hline Total & $\mathbf{6}$ & $\mathbf{2 4}$ & $\mathbf{1 1}$ & $\mathbf{4 1}$ \\
\hline
\end{tabular}

Quadro 6: Objeto de estudo

Os trabalhos selecionados também foram analisados de acordo com o enfoque dado no objeto de estudo. Ou seja, analisamos os estudos de acordo com o objetivo geral proposto. A partir dessa análise, os trabalhos foram agrupados em quatro categorias: gestão, organização e estrutura; comunidade; espaços e equipamentos; produção acadêmica. Os trabalhos classificados como "gestão, organização e estrutura" foram aqueles que investigaram as políticas sociais de esporte e lazer a partir da análise da gestão e/ou organização e/ou estrutura dessas ações sociais. Os trabalhos classificados como "comunidade" foram aqueles que investigaram as políticas sociais de esporte e lazer a partir da análise de ações e/ou perspectivas das comunidades acerca delas mesmas, elencando temas como participação e envolvimento popular, por exemplo. Os trabalhos classificados como "espaços/equipamentos" foram os que problematizaram as políticas sociais de esporte e lazer a partir da investigação dos espaços e/ou equipamentos utilizados. Os trabalhos classificados como "produção acadêmica" foram aqueles que visaram investigar a temática de políticas sociais de esporte e lazer a partir da produção acadêmica. 
Observamos que a maior parte dos trabalhos, 29 no total, problematizou as políticas sociais de esporte e lazer a partir de sua gestão e/ou organização e/ou estrutura. Não encontramos trabalhos de doutorado e mestrado que investigaram a temática de políticas sociais a partir da produção acadêmica. Também não encontramos trabalhos que abordaram a temática a partir dos espaços e/ou equipamentos em nível de doutorado. Os artigos de periódicos foram as publicações que apresentaram maior equidade em relação ao enfoque dado no objeto de estudo (Quadro 7).

\begin{tabular}{|l|c|c|c|c|c|}
\hline & $\begin{array}{c}\text { Gestão, } \\
\text { organização } \\
\text { e estrutura }\end{array}$ & Comunidade & $\begin{array}{c}\text { Espaços/equipa- } \\
\text { mentos }\end{array}$ & $\begin{array}{c}\text { Produção } \\
\text { acadêmica }\end{array}$ & Total \\
\hline Dissertações & 20 & 4 & 1 & - & $\mathbf{2 5}$ \\
\hline Teses & 6 & 1 & - & - & 7 \\
\hline $\begin{array}{l}\text { Artigos de } \\
\text { periódicos }\end{array}$ & 3 & 2 & 3 & 1 & $\mathbf{9}$ \\
\hline Total & $\mathbf{2 9}$ & $\mathbf{7}$ & $\mathbf{4}$ & $\mathbf{1}$ & $\mathbf{4 1}$ \\
\hline
\end{tabular}

Quadro 7: Objeto do estudo

\section{Considerações finais}

Antes de apontarmos algumas considerações finais, gostaríamos de reconhecer algumas das limitações do trabalho. Ao restringirmos nossas buscas aos trabalhos disponibilizados nas bases on-line, não incluímos em nossas análises muitos trabalhos acerca da temática de políticas sociais de esporte e lazer, visto que a divulgação on-line é recente. Também reconhecemos que ao utilizarmos as palavras-chave "políticas públicas de esporte", "políticas públicas de lazer", "políticas de esporte" e "políticas de lazer" para realizarmos a busca alguns trabalhos, ainda que não utilizem tais termos, mas que discutam políticas sociais de esporte e lazer, podem não ter sido por nós selecionados. No entanto, acreditamos que os dados levantados apresentam um panorama geral da produção acadêmica acerca das políticas sociais de esporte e lazer no que diz respeito às teses, dissertações e artigos de periódicos no período de 2000 a 2009.

A partir desse mapeamento, percebemos que, apesar de existir um aumento no número de estudos que abordam a temática de políticas sociais de esporte e lazer, essa temática não tem sido uma constante nas produções científicas, principalmente no que diz respeitos às teses e artigos de periódicos. Em relação a dissertações e teses, observamos 
um maior número de trabalhos na Universidade Metodista de Piracicaba e na Universidade Estadual de Campinas. Em relação aos periódicos, a maior parte dos trabalhos foi encontrada na Revista Movimento.

Em relação à metodologia dos trabalhos, conforme aponta Ferreira (2002), muitos deles não demonstram clareza em relação aos aspectos metodológicos. Constatamos que há uma predominância de trabalhos de natureza qualitativa e a inexistência de trabalhos de natureza quantitativa. A combinação entre análise documental e pesquisa de campo foi a modalidade de pesquisa mais frequente.

Constatamos que o lazer tem sido o principal objeto de estudo nos trabalhos sobre as políticas sociais e que, ao problematizar as políticas sociais de esporte e lazer, a maior parte dos trabalhos investiga tais ações a partir da análise de sua gestão e/ou organização e/ou estrutura.

Levando-se em consideração os achados desta pesquisa, apontamos que ainda são poucos os estudos que investigam políticas sociais de esporte e lazer a partir de pesquisas de natureza quantitativa. Também concluímos que são necessárias mais pesquisas que abordem as políticas sociais de esporte e lazer a partir de um enfoque nas políti-

State of the art of social policy in sports and leisure in Brazil (2000-2009)

\begin{abstract}
This paper aims conduct at mapping of theses, dissertations and articles available online that address social policies of sports and leisure in the period from 2000 to 2009. A total of 32 studies have been selected. The conclusion is that, despite an increase in the number of studies addressing the issue of social sports and recreation, it has been realized that this issue has not been a constant in scientific production. There is a predominance of qualitative work and a lack of quantitative works. Leisure has been the major object of studies in works on social policies. Another conclusion is that most of the works to discuss social policies for sports and leisure investigates such actions from the analysis of their management and / or organization and / or structure.
\end{abstract}

Keywords: Public Policy. Sports. Leisure.

El estado del arte de la política social del deporte y del ocio en Brasil (20002009)

\title{
Resumen
}

Este trabajo pretende realizar un levantamiento de las tesis, tesinas y artículos disponibles on line que se ocupan de las políticas sociales del deporte y del ocio de 2000 a 2009. En total, 32 trabajos fueron seleccionados. Se puede concluir que, a 
pesar de un aumento el en número de estudios que abordan la cuestión de las políticas sociales para el deporte y el ocio, está claro que esta cuestión no ha sido una constante en la producción científica. Hay un predominio de las obras de naturaleza cualitativa e inexistencia de trabajos de naturaleza cuantitativa. El ocio ha sido el principal objeto de estudio en los trabajos sobre políticas sociales. Otra conclusión fue que la mayor parte de los trabajos al discutir las políticas sociales del deporte y del ocio, investiga esas acciones a partir del análisis de su gestión y/u organización y/o estructura.

Palabras clave: Política Social. Deporte. Ocio.

\section{Referências}

AMARAL, S. C. F.; PEREIRA, A. P. C. Reflexões sobre a produção em políticas públicas de educação física, esporte e lazer. Revista Brasileira de Ciências do Esporte, Campinas, v. 31, n. 1, p. 7-239, set. 2009. Disponível em: <http://www.ufsj.edu.br/portal-repositorio/File/dcefs/Prof._Adalberto_Santos2/25-reflexoes_sobre_a_producao_em_politicas_publicas_em_ef_lazer16.pdf $>$. Acesso em: $1 \mathrm{dez}$. 2010 .

BRASIL. Constituição (1988). Constituição da República Federativa do Brasil. Brasília, DF: Senado, 1988. Disponível em: $<$ http://www.senado.gov.br/sf/legislacao/const/con1988/CON1988_05.10.1988/index.htm>. Acesso em: 5 maio 2009 .

FERREIRA, A. L. P. O estado da arte da sociologia do esporte no Brasil: um mapeamento da produção bibliográfica de 1997 a 2007. 2009. 269 f. Dissertação (Mestrado em Sociologia) - Programa de Pós-Graduação em Sociologia, Universidade Federal do Paraná, Curitiba, 2009. Disponível em: <http://www.pgsocio.ufpr.br/docs/defesa/dissertacoes/2009/analeticia.pdf $>$. Acesso em: 1 dez. 2010.

FERREIRA, N. S. de A. As pesquisas denominadas "estado da arte". Revista Educação \& Sociedade, ano 23, n. 79, ago. 2002. Disponível em: <http://www.scielo.br/pdf/es/v23n79/10857.pdf>. Acesso em: 1 dez. 2010.

GODOY, L.; VENDRUSCOLO; R. Desafios da produção de conhecimentos sobre políticas públicas para o esporte e o lazer no Brasil. In: CONGRESSO BRASILEIRO DE SOCIOLOGIA, 15., 2011, Curitiba. Anais... Curitiba: SBS, 2011. Disponível em: <http://www.sistemas- 
mart.com.br/sbs2011/inscricao/visualiza_popup1.asp?IdAtividade $=1579>$. Acesso em: 15 fev. 2011.

HÖLFING, E. de M. Estado e políticas (públicas) sociais. Caderno Cedes, ano 21, n. 55, nov. 2001, p. 30-41. Disponível em: $<$ http://www.scielo.br/pdf/ccedes/v21n55/5539.pdf $>$. Acesso em: 15 nov. 2010.

LINHALES, M. A. A trajetória política do esporte no Brasil: interesses envolvidos, setores excluídos. 1996. 242 f. Dissertação (Mestrado) - Faculdade de Filosofia e Ciências Humanas, Universidade Federal de Minas Gerais, Belo Horizonte, 1996.

LINHALES, M. A. São as políticas públicas para a educação física/esportes e lazer, efetivamente políticas sociais? Motrivivência, Florianópolis, ano 10, n. 11, p. 71-81, jul. 1998.

LINHALES, M. A. Jogos de política, jogos de esporte. In: MARCELLINO, N. C. (Org.). Lazer e esporte. 2. ed. Campinas: Autores Associados, 2001. p. 31-56.

MINISTÉRIO DO ESPORTE. Secretaria Nacional de Desenvolvimento de Esporte e Lazer. Disponível em: <http://www.esporte.gov.br/sndel/sobre.jsp>. Acesso em: 1 nov. 2010.

STIGGER, M. P. Políticas sociais em lazer, esportes e participação: uma questão de acesso e de poder; ou subsídios para tomar uma posição frente à pergunta: "são as políticas públicas para educação física, esportes e lazer, efetivamente políticas sociais?". Motrivivência, Florianópolis, ano 10, n. 11, p. 84-96, jul. 1998.

Recebido em: 03/04/2011

Revisado em: 18/07/2011

Aprovado em: 25/11/2011

Endereço para correspondência

neusamoro@gmail.com

Neuza Rosa Nery de Lima Moro

Universidade Federal do Paraná, Setor de Ciências da Saúde.

Av. Lothário Meissnes. 3.400

Jardim Botânico

80220-170 - Curitiba, PR - Brasil

Pensar a Prática, Goiânia, v. 15, n. 2, p. 272-550, abr./jun. 2012 